\title{
Hubungan Metode Pembelajaran Diskusi Buzz Group dengan Aktivitas Belajar Siswa pada Mata Pelajaran IPS Terpadu
}

\author{
Deliana Nifu, Hadi Gunawan Sakti \\ Program Studi Teknologi Pendidikan, FIPP UNDIKMA \\ Corresponding Author. Email: gunawansakti33@gmail.com
}

\begin{abstract}
The purpose of this study was to determine the relationship between the buzz group discussion learning method with student learning activities in Integrated Social Studies subjects Class VIII at SMPN 4 Praya Barat Daya. The method used in this research is correlational with a questionnaire as the main method, observation and documentation as a complementary method. This study took a sample of class VIII students. B at SMPN 4 Praya Barat Daya, Central Lombok. The data analysis in this study used a quantitative approach using the Moment Product Correlation. Based on the results of data analysis, the correlation coefficient was found to be 0.405 . Based on $\mathrm{N}=14$ with a significance level of $5 \% \mathrm{r}$ table of 0.553 . This means that rtabel is greater than rcount, namely $0.553>0.405$, so it can be concluded that there is a relationship between the Buzz Group discussion learning method and student learning activities in integrated social studies subjects Class VIII at SMPN 4 Praya Barat.
\end{abstract}

Abstrak: Tujuan penelitian ini adalah ingin mengetahui hubungan antara metode pembelajara diskusi buzz group dengan aktivitas belajar siswa pada mata pelajaran IPS Terpadu Kelas VIII Di SMPN 4 Praya Barat Daya. Metode yang digunakan dalam penelitian ini adalah korelasional dengan angket sebagai metode pokok, observasi dan dokumentasi sebagai metode pelengkap. Penelitian ini mengambil sampel siswa kelas VIII. B di SMPN 4 Praya Barat Daya Lombok Tengah. Analisis data dalam penelitian ini menggunakan pendekatan kuantitatif dengan menggunakan Korelasi Produk Momen. Berdasarkan hasil analisis data koefisien korelasi yang ditemukan sebesar 0,405. Berdasarkan $\mathrm{N}=14$ dengan taraf signifikansi 5\% rtabel sebesar 0,553. Artinya rtabel lebih besar dari rhitung yaitu 0,553>0,405 sehingga dapat dsimpulkan bahwa ada hubungan antara metode pembelajaran diskusi Buzz Group dengan aktivitas belajar siswa pada mata pelajaran IPS terpadu Kelas VIII Di SMPN 4 Praya Barat.

How to Cite: Nifu, D., \& Sakti, H. (2020). Hubungan Metode Pembelajaran Diskusi Buzz Group dengan Aktivitas Belajar Siswa pada Mata Pelajaran IPS Terpadu. Jurnal Teknologi Pendidikan, 5(2), 144-149. Retrieved from http://ojs.ikipmataram.ac.id/index.php/itp/article/view/3075

\section{Pendahuluan}

Perkembangan Teknologi mempengaruhi setiap bidang dan aspek kehidupan, termasuk bidang pendidikan. Dewasa ini sesuai dengan perkembangannya yang digunakan adalah teknologi maju seperti audio dan video cassette, overhead, CD-room dan internet. Penerapan teknologi dalam bidang pendidikan khususnya kurikulum adalah dalam dua bentuk, yaitu bentuk perangkat lunak dan perangkat keras.Teknologi pendidikan dalam arti teknologi alat, lebih menekankan kepada penggunaan alat-alat teknologis untuk menunjang efesiensi dan efektivitas pendidikan. Kurikulumnya berisi rencana-rencana penggunaan berbagai alat dan media, juga model-model pengajaran yangbanyak melibatkan penggunaan alat. Dalam arti teknologi system, teknologi pendidikan menekankan kepada penyusunan program pengajaran atau rencana pembelajaran dengan menggunakan pendekatan system yang ditunjang dengan alat media, dan juga program system yang dipadukan dengan alat dan media pengajaran. 
Pengajaran IPS sangat penting bagi jenjang pendidikan dasar dan menengah karena siswa yang datang ke sekolah berasal dari lingkungan yang berbeda-beda. Pengenalan mereka tentang masyarakat tempat mereka menjadi anggota diwarnai oleh lingkungan mereka tersebut. Sekolah bukanlah satu-satunya wahana atau sarana untuk mengenal masyarakat. Para siswa dapat belajar mengenal dan mempelajari masyarakat baik melalui media cetak maupun elektronika, misalnya melalui acara televisi, siaran radio, dan membaca koran.

Metode pembelajaran di sekolah biasanya bersifat klasik melalui metode konvensional,yaitu metode pembelajaran yang menggunakan sistem ceramah, dan tanya jawab antara guru dengan siswa. Dalam menentukan metode pembelajaran, guru juga harus memperhatikan faktor siswa sebagai subyek belajar. Upaya untuk meningkatkan aktivitas belajar siswa tidak terlepas dari berbagai faktor yang mempengaruhinya. Dalam hal ini, guru perlu kreatif dan mampu memilih metode yang sesuai agar pembelajaran lebih menarik dan menyenangkan, sehingga siswa akan menyukai pembelajaran tersebut.

Metode Buzz Group merupakan diskusi pada satu kelompok besar yang dibagi menjadi beberapa kelompok kecil, terdiri atas 3 sampai 4 orang. Tempat duduk diatur sedemikian agar siswa dapat bertukar pikiran dan berhadapan muka dengan mudah. Diskusi diadakan di tengah-tengah pelajaran atau di akhir pelajaran dengan maksud memperjelas bahan pelajaran atau menjawab pertanyaan-pertanyaan. Metode Buzz group memungkinkan siswa mampu bekerja sama dan bertukar pikiran dalam Sehubungan dengan hal tersebut, maka metode pembelajaran Buzz Group diharapkan mampu memecahkan permasalahan di atas sehingga hasil belajar mengajar dapat tercapai dengan maksimal.

Menurut Bahtiar (2010), diskusi dengan menggunakan metode Buzz Group adalah diskusi pada satu kelompok besar yang dibagi menjadi beberapa kelompok kecil, terdiri atas 3 sampai 4 orang. Tempat duduk diatur sedemikian agar siswa dapat bertukar pikiran dan berhadapan muka dengan mudah. Diskusi diadakan di tengah-tengah pelajaran atau diakhir pelajaran dengan maksud, memperjelas bahan pelajaran atau menjawab pertanyaan-pertanyaan. Menurut Hasibuan \& Moedjiono (2006), diskusi jenis Buzz Group adalah satu kelompok besar dibagi menjadi beberapa kelompok kecil, terdiri atas 4-5 orang. Tempat diatur agar siswa dapat berhadapan muka dan bertukar pikiran dengan mudah.Diskusi dapat dilakukan ditengah atau diakhir pelajaran dengan maksud memperjelas bahan pelajaran, atau menjawab pertanyaan-pertanyaan. Berdasarkan beberapa pendapat di atas, dapat disimpulkan bahwa pengertian diskusi kelompok kecil (Buzz Group Discussion) adalah sebuah kelompok besar yang berkumpul dan dibagi menjadi kelompok-kelompok kecil sekitar 3-6 orang, untuk mendiskusikan masalah tertentu dalam waktu yang singkat. Menurut Apriyantini dkk, (2012) bahwa aktivitas adalah keterlibatan dalam proses pembelajaran yang ditunjukan dengan peranan siswa sebagai pelaku dalam kegiatan belajar. Aktivitas siswa dalam pembelajaran sangat diperlukan sehingga berdampak pada hasil belajar.Namun ketika siswa pasif, kurang aktif dan hanya menerima informasi dari pendidik, ada kecenderungan untuk melupakan informasi yang diterimanya. Sedangkan menurut Wahdah M Tahir dkk, (2012) menyatakan bahwa aktivitas belajar merupakan segala kegiatan yang dilakukan dalam proses pembelajaran antara interaksi guru dan siswa dalam rangka mencapai tujuan belajar. Dari uraian di atas, maka disimpulkan bahwa aktivitas belajar siswa adalah proses 
pembelajaran berlangsung, baik kegiatan antara siswa dengan guru, kegiatan antara siswa dengan siswa lainnya maupun kegiatan antara siswa dengan lingkungannya.

Adapun tujuan penelitian ini adalah untuk menganalisis hubungan antara metode pembelajaran diskusi buzz group dengan aktivitas belajar siswa pada mata pelajaran IPS terpadu kelas VIII di SMPN 4 Praya Barat Daya Kabupaten Lombok Tengah.

\section{Metode Penelitian}

Metode penelitian yang digunakan dalam penelitian ini adalah penelitian korelasi. Pada penelitian ini teknik penarikan sampel menggunakan teknik acak berkelompok (Cluster Random Sampling) dengan jenis satu tahap (A Stage Cluster Random Sampling yang lebih dikenal dengan Cluster Random Sampling). Yaitu, penentuan sampel dengan menggunakan cara acak sederhana, dengan membuat undian nama kelas VIII A dan VIII B kemudian memilihnya secara acak, nama kelas yang terpilih akan menjadi sampel penelitian. Sehingga dalam penelitian ini didapatkan kelas VIII B sebagai sampel penelitian setelah melakukan acak berkelompok dengan satu tahap.

Untuk mengetahui hubungan metode pembelajaran diskusi Buzz Group dengan Aktivitas Belajar Siswa digunakan instrumen berupa kuesioner (angket). Kuesioner yang digunakan dalam hal ini adalah kuesioner tertutup, yakni kuesioner yang sudah disediakan jawabannya, sehinggaresponden tinggal memilih dan menjawab secara langsung sesuai dengan keadaan yang dirasakan oleh responden. Selain itu item pertanyaan yang diajukan dan disediakan pula alternatif jawaban. Oleh sebab itu, data kuesioner berupa kualitatif maka perlu diubah menjadi data kuantitatif dengan menggunakan simbol angka.Adapun item pertanyaan yang diajukan pada kuesioner ini berjumalah 30 item dan disediakan 4 alternatif jawaban. Untuk setiap item pertanyaan diberi skor satu sampai dengan empat, yaitu sangat setuju, setuju, tidak setuju, sangat tidak setuju.Teknik pengumpulan data merupakan langkah yang paling strategis dalam penelitian,karena tujuan utama dalam penelitian adalah mendapatkan data. Tanpa mengetahui teknik pengumpulan data, maka peneliti tidak akan mendapatkan data yang memenuhi standar data yang ditetapkan (Sugiyono, 2014). Jadi langkah yang paling utama dalam penelitian ini adalah untuk mendapatkan data yang memenuhi standar data yang ditetapkan. Sehingga dalam penelitian ini digunakan angket, observasi, dan dokumentasi sebagai metode pelengkap. Teknik analisis data yang digunakan dalam penelitian ini adalah analisis data statistik dengan menggunakan rumus Product Moment Correlation (Sugiyono, 2014).

\section{Hasil Penelitian dan Pembahasan}

Dari hasil analisis di atas maka koefisien korelasi yang ditemukan sebesar 0,405 termasuk pada kategori signifikan. Dari hasil Korelasi Produk Momen menunjukkan nilai $\mathrm{r}_{\text {hitung }}$ sebesar 0,405 maka berdasarkan taraf signif 5\% dan $\mathrm{N}=14$. Ternyata besar angka batas penolakan hipotesis nihil yang dinyatakan dalam $r_{\text {tabel }}$ adalah 0,532. Kenyataan ini menunjukkan bahwa $r_{\text {tabel }}$ lebih besar dari pada $r_{\text {hitung }}(0,405<0,532)$ karena $r_{\text {tabel }}$ lebih besar dari pada $r_{\text {hitung }}$ dengan demikian hipotesis alternatif (Ha) yang berbunyi ada hubungan antara metode pembelajaran diskusi buzz group dengan aktivitas belajar siswa pada mata pelajaran IPS terpadu kelas VIII di SMPN 4 Praya Barat Daya”. Adapun hipotesis nihil (Ho) yang berbunyi tidak ada hubungan antara metode pembelajaran diskusi buzz group dengan aktivitas belajar siswa pada mata pelajaran IPS terpadu kelas VIII di SMPN 4 Praya Barat Daya "diterima". Maka dapat di tarik kesimpulan bahwa tidak ada hubungan antara 
metode pembelajaran diskusi buzz group dengan aktivitas belajar siswa pada mata pelajaran IPS terpadu kelas VIII di SMPN 4 Praya Barat Daya.

Berdasarkan penelitian yang telah dilakukan dengan penggunaan metode Buzz Group diperoleh hasil berupa data yang berupa angka yang kemudian di olah. Dari analisis data tentang penggunaan metode Buzz Group dengan aktivitas belajar siswa maka koefisien korelasi yang ditemukan sebesar 0,405 termasuk pada kategori sangat kuat. Dari hasil Korelasi Produk Momen menunjukkan $\mathrm{r}_{\text {hitung }}$ sebesar 0,405 maka berdasarkan taraf signif $5 \% \mathrm{~N}=14$. Ternyata besar angka batas penolakan hipotesis nihil yang dinyatakan dalam rtabel adalah 0,532. Kenyataan ini menunjukkan bahwa $r_{\text {tabel }}$ lebih besar dari pada $r_{\text {tabel }}(0,405<0,532)$ karena $r_{\text {tabel }}$ lebih besar dari $r_{\text {hitung dengan demikian hipotesis }}$ alternatif (Ha) yang berbunyi ada hubungan antara metode pembelajaran diskusi buzz group dengan aktivitas belajar siswa pada mata pelajaran IPS terpadu kelas VIII di SMPN 4 Praya Barat Daya di "ditolak". Adapun hipotesis nihil (Ho) yang berbunyi tidak ada hubungan antara metode pembelajaran diskusi buzz group dengan aktivitas belajar siswa pada mata pelajaran IPS terpadu kelas VIII di SMPN 4 Praya Barat Daya "diterima". Maka dapat di tarik kesimpulan bahwa tidak ada hubungan antara metode pembelajaran diskusi buzz group dengan aktivitas belajar siswa pada mata pelajaran IPS terpadu kelas VIII di SMPN 4 Praya Barat Daya.

Metode Buzz Group merupakan diskusi pada satu kelompok besar yang dibagi menjadi beberapa kelompok kecil, terdiri atas 3 sampai 4 orang. Tempat duduk diatur sedemikian agar siswa dapat bertukar pikiran dan berhadapan muka dengan mudah. Diskusi diadakan di tengah-tengah pelajaran atau di akhir pelajaran dengan maksudmemperjelas bahan pelajaran atau menjawab pertanyaan-pertanyaan. Metode Buzz group memungkinkan siswa mampu bekerja sama dan bertukar pikiran dalam memecahkan suatu masalah dan siswa mampu berinteraksi dengan guru. Sedangkan Zaenal (2002), mengemukakan bahwa metode pembelajaran diskusi merupakan suatu pembelajaran yang dicirikan oleh suatu ketertarikan pada suatu topik atau pokok pertanyaan atau masalah,dimana para peserta diskusi dengan jujur berusaha untuk mencapai atau memperoleh suatu keputusan atau pendapat yang disepakati bersama.

Jadi, metode pembelajaran diskusi adalah suatu metode pembelajaran yang dicirikan oleh suatu ketertarikan pada suatu topik atau masalah, dimana didalamnya terdapat sutau proses interaksi antara dua atau lebih individu yang terlibat dalam kelompok belajar, saling tukar menukar informasi/pendapat, serta pengalaman dalam memecahkan masalah untuk mengambil suatu kesimpulan. Menurut Apriyantini dkk, (2012) bahwa aktivitas adalah keterlibatan dalam proses pembelajaran yang ditunjukan dengan peranan siswa sebagai pelaku dalam kegiatan belajar. Aktivitas siswa dalam pembelajaran sangat diperlukan sehingga berdampak pada hasil belajar.Namun ketika siswa pasif, kurang aktif dan hanya menerima informasi dari pendidik, ada kecenderungan untuk melupakan informasi yang diterimanya. Sedangkan menurut Wahdah M Tahir dkk, (2012) menyatakan bahwa aktivitas belajar merupakan segala kegiatan yang dilakukan dalam proses pembelajaran antara interaksi guru dan siswa dalam rangka mencapai tujuan belajar. Dari uraian di atas, maka disimpulkan bahwa aktivitas belajar siswa adalah proses pembelajaran berlangsung, baik kegiatan antara siswa dengan guru, kegiatan antara siswa dengan siswa lainnya maupun kegiatan antara siswa dengan lingkungannya. 


\section{Kesimpulan}

Berdasarkan hasil penelitian yang telah dilakukan dapat disimpulkan bahwa ada hubungan antara metode pembelajaran diskusi buzz group dengan aktivitas belajar siswa pada mata pelajaran IPS terpadu kelas VIII di SMPN 4 Praya Barat Daya. Hal ini di buktikan dengan keosisien korelasi yang di temukan sebesar 0,405 dan hasil dari $\mathrm{r}_{\text {tabel }}$ lebih besar dari $r_{\text {hitung }}$ yaitu $r_{\text {hitung }}=0,532>r_{\text {tabel }}=0,405$.

\section{Saran}

Berdasarkan dari simpulan yang diperoleh dari hasil penelitian ini maka dapat disarankan sebagai berikut: 1) Bagi Siswa. Bagi siswa khususnya siswa kelas VIII SMP Negeri 4 Praya Barat Daya diharapkan untuk selalu semangat, aktif, kritis dalam kegiatan belajar. Selain itu dengan modal ini secara langsung akan membantu siswa untuk menjadi siswa yang aktif dalam proses pembelajaran, 2) Bagi Guru. Diharapkan lebih kreatif mengemas metode pembelajaran diskusi buzz group menjadi lebih menarik agar suasana proses pembelajaran menjadi lebih kondusif sehingga mempermudah siswa untuk menyerap materi yang diajarkan dan mendorong minat siswa terhadap mata pelajaran IPS Terpadu, 3) Bagi Peneliti. Selanjutnya Kepada peneliti lainnya hendaknya menggunakan metode diskusi buzz group pada materi belajar yang berbeda sesuai dengan karakteristik materi ajar yang disampaikan sebagai upaya meningkatkan aktivitas belajar siswa menjadi lebih optimal.

\section{Daftar Pustaka}

AECT. (2004). Instructional Technology. New York \& London: Lawrence Erlbaum Associates.

Apriyantini dkk. (2012). Peningkatan Aktivitas pembelajaran matematika dengan menggunakan metode Problem Solving pada siswa kelas IV Jurusan Pendidikan dasar FIP Universitas Tanjung Pura Pontianak.

Bahtiar. (2010). Modul Strategi belajar mengajar sains (IPA) fisika program studi pendidikan fisika,FIP Universitas Muhamadiyah Mataram.

Hasibuan \& Moedjiono. (2006). Proses belajar mengajar.Bandung:Remaja Rosdakarya

Fitriani, F. (2017). PENGARUH METODE PEER TUTORING MELALUI PENDEKATAN SAINTIFIK TERHADAP AKTIVITAS BELAJAR SISWA PADA MATA PELAJARAN BAHASA INDONESIA. Jurnal Teknologi Pendidikan, 2(2), 17-22. Retrieved from http://ojs.ikipmataram.ac.id/index.php/jtp/article/view/589

Hamalik. (2009). Proses belajar mengajar. Jakarta: Bumi Aksara.

Ikawati, H., \& Anwar, Z. (2018). MODEL DISKUSI DAN PENGARUHNYA TERHADAP PENGUASAAN MATERI MATA KULIAH PENGANTAR TEKNOLOGI PENDIDIKAN. Jurnal Paedagogy, 5(1). doi:https://doi.org/10.33394/jp.v5i1.2589

Mulyani, N. (2020). Meningkatkan Aktivitas Belajar Peserta Didik pada Mata Pelajaran PAI dan Budi Pekerti Melalui Pembelajaran Kooperatif Model Mind Mapping dalam Bentuk Peta Konsep Kreatif di SMP Negeri 1 Pemenang. Jurnal Paedagogy, 7(3), 244-251. doi:https://doi.org/10.33394/jp.v7i3.2730

Pratini, P. (2015). Upaya Meningkatkan Aktivitas dan Hasil Belajar PKn Siswa Kelas VIII-B SMPN 18 Mataram Melalui Penerapan Pendekatan Cooperative Learning Tipe Jigsaw. Jurnal Kependidikan: Jurnal Hasil Penelitian dan Kajian Kepustakaan di Bidang Pendidikan, Pengajaran dan Pembelajaran, 1(2). doi:https://doi.org/10.33394/jk.v1i2.417 
Riyadi, S. (2015). Implementasi Metode Diskusi dan Resitasi dalam Meningkatkan Prestasi Belajar Mata Pelajaran PKn Siswa Kelas V SDN Ambat. Jurnal Kependidikan: Jurnal Hasil Penelitian dan Kajian Kepustakaan di Bidang Pendidikan, Pengajaran dan Pembelajaran, 1(2). doi:https://doi.org/10.33394/jk.v1i2.424

Rosidha, A. (2020). Peningkatan Aktivitas dan Hasil Belajar Siswa pada Mata Pelajaran Biologi Melalui Model Pembelajaran Make and Match Berbasis Media Karu Pintar. Jurnal Paedagogy, 7(4), 393-401. doi:https://doi.org/10.33394/jp.v7i4.2946

Suharsimi Arikunto. (2010). Prosedur penelitian Suatu Pendekatan Praktek Edisi revisi Jakarta: PT. Rineka Cipta.

Wakhidah, W. (2016). PENINGKATKAN MOTIVASI DAN HASIL BELAJAR SISWA MELALUI METODE DISKUSI KELOMPOK PADA PEMBELAJARAN BAHASA JAWA KELAS VI SD NEGERI 03 POJOK KARANGANYAR. Jurnal Teknologi Pendidikan, $1(2), \quad 1-9 . \quad$ Retrieved from http://ojs.ikipmataram.ac.id/index.php/jtp/article/view/607 